\title{
The Importance of Synchronization During Neonatal Noninvasive Ventilation
}

Primary use of nasal CPAP in premature infants with respiratory distress syndrome has been associated with improved outcomes. ${ }^{1,2}$ Avoiding intubation and invasive ventilation may reduce injury, inflammation, pulmonary growth arrest, and development of chronic lung disease. ${ }^{3,4}$ However, nearly half of all neonates initially supported with CPAP will develop respiratory failure severe enough to require intubation for short-term invasive ventilation and surfactant administration. ${ }^{5}$

Noninvasive ventilation (NIV) is a form of respiratory assistance that provides greater support than CPAP and may prevent intubation in a larger fraction of neonates who would otherwise fail CPAP and receive invasive ventilation. NIV combines CPAP with positive pressure during inspiration to offload intrinsic efforts, and improve ventilation and lung recruitment. ${ }^{1}$ NIV breaths may be patient triggered and, thus, "synchronized," or non-synchronized. NIV has been used to avoid intubation ${ }^{6-8}$ and facilitate extubation. ${ }^{9}$ NIV may be more lung protective and promote alveolar growth and development better than invasive ventilation. ${ }^{10,11}$ Compared with CPAP, NIV has been associated with greater tidal volume and minute ventilation, reduced thoraco-abdominal asynchrony, ${ }^{12}$ lower breathing frequency, improved gas exchange, ${ }^{13}$ and reduced work of breathing (WOB) ${ }^{14,15}$ as well as reduction in the magnitude and/or severity of apneic episodes ${ }^{9,16}$ and the need for invasive ventilation. ${ }^{17}$

Although these NIV findings seem promising, premature infants in many of these studies were primarily supported with synchronized NIV, not non-synchronized NIV, by using a ventilator that is no longer commercially available. The Infrasonics Infant Star ventilator with the StarSynch module was unique in that it permitted synchronized NIV based on pressure changes from diaphragm descent within an abdominal (Graseby) capsule attached

Mr DiBlasi has disclosed relationships with Vero Biotech, Mallinckrodt Medical, Vapotherm, Aerogen Pharma, Neotech, and Draeger Medical.

Correspondence: Robert M DiBlasi RRT RRT-NPS FAARC, Seattle Children's Research Institute - Respiratory Care, Center for Developmental Therapeutics Toxicology and Pharmacology, 1900 Ninth Avenue Seattle WA 98101. E-mail: robert.diblasi@seattlechildrens.org.

DOI: $10.4187 /$ respcare.06741 below the xiphoid process. This method for synchronized NIV reportedly provided consistent triggering, independent of leak. ${ }^{18}$

See the Original Study on Page 1478

The abdominal capsule continues to be used with synchronized NIV devices in Europe. ${ }^{19}$ After discontinuation of the Infant Star, clinicians have been left with very few options for providing neonatal synchronized NIV in the United States. Ventilator manufacturers have attempted to support the neonatal synchronized NIV niche market and address the need by incorporating synchronized NIV modes with advanced flow-triggering algorithms. However, these synchronized NIV modes may have difficulty with providing synchrony in premature infants. ${ }^{20}$ There is a delicate technologic balance between having a system that is sensitive enough to detect infants' weak efforts while still being able to avoid auto-triggering in the presence of variable nasal and/or oral leaks. Patient WOB, synchrony, and other outcomes with flow-triggered synchronized NIV have not been studied clinically.

Manufacturers continue to explore novel synchronized NIV triggering options with surface electromyography, inductance bands, hot-wire flow sensors, and other noninvasive signals. Clinicians are seeking a safe, accurate, and reliable synchronized NIV mode now, more than ever before, to prevent intubation and avoid lung injury. Although synchrony is preferred, it is difficult to measure and may not always be associated with improved outcomes when compared between synchronized and non-synchronized NIV. Early studies that enrolled hundreds of premature infants and that compared synchronized with non-synchronized invasive modes of ventilation, showed no differences in major outcomes or complications. ${ }^{21}$ Because of the technologic limitations and lack of synchronized NIV modes, many clinicians continue to have success with using non-synchronized NIV modes, and, thus, the superiority of synchronized NIV over non-synchronized NIV remains inconclusive. ${ }^{22} \mathrm{New}$ research has left many clinicians wondering whether synchronized NIV modes are even necessary or if synchrony is needed to improve outcomes in premature infants. This debate has sparked na- 


\section{EDITORIALS}

tional controversy across American neonatal ICUs over the past decade.

Currently, the most promising synchronized NIV mode for premature infants is NIV neurally adjusted ventilatory assist (NAVA). In theory, NIV-NAVA should result in optimal synchrony because it provides triggering and the timing and magnitude of the positive pressure breath is based on the electrical activity of the diaphragm acquired from an indwelling feeding tube. ${ }^{23,24}$ There is a paucity of clinical data related to NIV-NAVA but, based on findings from animal ${ }^{23}$ and human studies, ${ }^{25,26}$ it seems to be a reasonable and safe synchronized NIV approach. A common outcome or theme from these studies was that NIVNAVA has been shown to improve synchrony. One study that compared NIV-NAVA with non-synchronized NIV in premature infants did not show notable differences in treatment failure or adverse events. ${ }^{27}$

In this issue of Respiratory CARE, Jones et $\mathrm{al}^{28}$ added to the growing body of NIV-NAVA evidence by comparing gas exchange and estimated WOB in spontaneously breathing piglets before and after surfactant lavage between synchronized NIV and NIV-NAVA. They found no differences in gas exchange, but there were differences in WOB, which favored NIV-NAVA. ${ }^{28}$ Investigators evaluated pressure-time product (PTP) as a surrogate for WOB. ${ }^{28}$ This method has previously been described to evaluate patientventilator asynchrony and WOB based on observed airway pressure changes with airway graphics in adults. ${ }^{29}$ Other investigators described a similar PTP method for calculating imposed WOB. ${ }^{30,31}$ However, calculated values of respiratory effort when using airway pressure signals may not always correlate well with direct measurement of work (esophageal pressure) and may actually underestimate the work being done by the patient. ${ }^{32,33}$ Also, this PTP calculation ${ }^{28,29}$ has not been validated in premature infants undergoing NIV.

It is important to note that airway pressure changes during NIV may be related to ventilator performance and less so to patient effort. NIV modes use leak compensation algorithms that will rapidly add flow to the circuit during the respiratory cycle. In these cases, the ventilator's contribution to airway pressure may limit detection of a premature infant's efforts, and calculated PTP may be underestimated. Studies that compare this PTP calculation with airway pressure need to be compared with direct measurement of PTP when using esophageal pressure. Lastly, PTP from the current study was calculated only for synchronized NIV breaths that were triggered by the subjects. ${ }^{28}$ Because all of the non-synchronized or non-subject-triggered breaths were excluded from analysis, important information about the subjects' WOB and ability to make an effort and actually receive a supported breath with synchronized NIV or NAVA is unknown. ${ }^{28}$ These data would have added to the utility of the article. NIV-NAVA may have many physiologic advantages over synchronized NIV, which has been shown to have a high asynchrony index. ${ }^{20}$

According to Subirà et al, ${ }^{34}$ accurate interpretation of cycle asynchronies would require monitoring not only usual ventilator waveforms but also esophageal pressure or electrical activity of the diaphragm. Esophageal pressure monitoring is the accepted method for direct measurements of patient-ventilator interaction. PTP that uses esophageal pressure is a validated method as an index of WOB estimated from esophageal pressure and is calculated by integrating pressure and time for the duration of contraction of the respiratory muscles. ${ }^{31}$ This measurement approximates energy expenditure of the respiratory muscles and closely estimates the metabolic cost of breathing and quantifies inspiratory effort for both isometric and non-isometric contraction.

In several studies, PTP and pressure-rate product measured with esophageal pressure monitoring has been used to evaluate indices of WOB in infants on NIV. ${ }^{18,35-38}$ Subject synchrony and measured PTP could have easily been addressed in the current study to evaluate synchronized and non-synchronized breaths. It is unclear why most neonatal studies that involve NIV-NAVA focus on synchrony and WOB in the absence of esophageal pressure. Esophageal pressure changes can still be measured when using existing gastric tubes ${ }^{39}$ or when an NIV-NAVA catheter ${ }^{23}$ is being used.

An important consideration when interpreting the findings of the present study ${ }^{28}$ is that synchrony was evaluated only for those breaths that were synchronized in the subjects. As such, the most important and clinically meaningful findings related to the subjects' inability to effectively synchronize intrinsic efforts with corresponding mechanical breaths were not included. Also, the subjects were sedated, interfaced with an oronasal mask, and used pressure triggering for synchronized NIV with a ventilator that has been shown to have high asynchrony in a bench model. ${ }^{20}$ So, it is unclear how these findings may be translated clinically.

Based on the current study and other studies that evaluated NIV-NAVA, results overwhelmingly support improved synchrony. There currently is no clinical association or correlation between asynchrony and an increased risk for death, much less chronic lung disease or any other complications in premature infants. Based on these observations, it could be argued that there is not enough evidence to suggest that NIV-NAVA or any other form of synchronized NIV is superior to non-synchronized NIV. There are remaining questions: (1) should patient-ventilator interaction or synchronization even be considered an important outcome in infants during NIV, and (2) is synchronized NIV or NIV-NAVA needed to provide NIV support in premature infants, even when non-synchronized NIV has still been shown to be effective? 
Findings from short-term physiologic studies on nonsynchronized NIV in premature infants demonstrated that asynchrony is common and may result in missed triggers, auto-triggering, or poor volume delivery to the lungs. ${ }^{40,41}$ Although synchronized NIV has been shown to reduce respiratory effort, no differences in hypoxic events, apneas, tidal volume, minute ventilation, and abdominal girth have been demonstrated when compared with non-synchronized NIV. ${ }^{18}$ In the absence of patient effort, nonsynchronized NIV in subjects with apnea, peak pressure has been shown to occasionally result in chest inflation and ameliorated oxygen desaturations. ${ }^{42}$ Patients are able to adapt to the ventilator within a short period, especially if the ventilator rate is set to at least $50 \%$ of their total breathing frequency. ${ }^{15}$

One clinical study showed lower incidence of chronic lung disease and length of support in premature infants with non-synchronized NIV than CPAP after extubation. ${ }^{43}$ A similar study showed a higher prevalence of re-intubation, post-extubation atelectasis, and mortality with premature infants supported with CPAP than with non-synchronized NIV. ${ }^{44}$ In a retrospective study that compared synchronized NIV with non-synchronized NIV in a cohort of 200 premature infants, after adjusting for disease severity, there were no differences in the combined outcome of bronchopulmonary dysplasia and death. ${ }^{45}$ Based on these findings with non-synchronized NIV, synchrony may not be important for predicting patient outcomes with NIV in premature infants.

Future studies are needed that use methods to measure esophageal pressure to determine whether NIV-NAVA reduces PTP and asynchrony in subjects. NIV-NAVA is likely to be very useful in the neonatal ICU setting but, until other clinically important outcomes, aside from synchrony, can be compared with non-synchronized NIV or other synchronized NIV modes, the technical complexity of use and cost related to this invasive NIV strategy will still need to be considered.

\section{Robert M DiBlasi RRT RRT-NPS FAARC}

Department of Respiratory Care

Seattle Children's Hospital and Research Institute Seattle, Washington

\section{REFERENCES}

1. DiBlasi RM. Neonatal noninvasive ventilation techniques: do we really need to intubate? Respir Care 2011;56(9):1273-1294; discussion 1295-1297.

2. Committee on Fetus and Newborn, American Academy of Pediatrics. Respiratory support in preterm infants at birth. Pediatrics 2014; 133(1):171-174.

3. Baraldi E, Filippone M. Chronic lung disease after premature birth. N Engl J Med 2007;357(19):1946-1955.
4. Diblasi RM. Nasal continuous positive airway pressure (CPAP) for the respiratory care of the newborn infant. Respir Care 2009;54(9): 1209-1235.

5. SUPPORT Study Group of the Eunice Kennedy Shriver NICHD Neonatal Research Network, Finer NN, Carlo WA, Walsh MC, Walsh MC, Rich W, et al. Early CPAP versus surfactant in extremely preterm infants. N Engl J Med 2010;362(21):1970-1979.

6. Sai Sunil Kishore M, Dutta S, Kumar P. Early nasal intermittent positive pressure ventilation versus continuous positive airway pressure for respiratory distress syndrome. Acta Paediatr 2009;98(9): $1412-1415$.

7. Manzar S, Nair AK, Pai MG, Paul J, Manikoth P, Georage M, Al-Khusaiby SM. Use of nasal intermittent positive pressure ventilation to avoid intubation in neonates. Saudi Med J 2004;25(10): 1464-1467.

8. Bhandari V, Gavino RG, Nedrelow JH, Pallela P, Salvador A, Ehrenkranz RA, Brodsky NL. A randomized controlled trial of synchronized nasal intermittent positive pressure ventilation in RDS. J Perinatol 2007;27(11):697-703.

9. Barrington KJ, Bull D, Finer NN. Randomized trial of nasal synchronized intermittent mandatory ventilation compared with continuous positive airway pressure after extubation of very low birth weight infants. Pediatrics 2001;107(4):638-641.

10. Lampland AL, Meyers PA, Worwa CT, Swanson EC, Mammel MC. Gas exchange and lung inflammation using nasal intermittent positive-pressure ventilation versus synchronized intermittent mandatory ventilation in piglets with saline lavage-induced lung injury: an observational study. Crit Care Med 2008;36(1):183-187.

11. Null DM, Alvord J, Leavitt W, Wint A, Dahl MJ, Presson AP, et al. High-frequency nasal ventilation for $21 \mathrm{~d}$ maintains gas exchange with lower respiratory pressures and promotes alveolarization in preterm lambs. Pediatr Res 2014;75(4):507-516.

12. Kiciman NM, Andréasson B, Bernstein G, Mannino FL, Rich W, Henderson C, Heldt GP. Thoracoabdominal motion in newborns during ventilation delivered by endotracheal tube or nasal prongs. Pediatr Pulmonol 1998;25(3):175-181.

13. Bhandari V, Finer NN, Ehrenkranz RA, Saha S, Das A, Walsh MC, et al.; Eunice Kennedy Shriver National Institute of Child Health and Human Development Neonatal Research Network. Synchronized nasal intermittent positive-pressure ventilation and neonatal outcomes. Pediatrics 2009;124(2):517-526.

14. Aghai ZH, Saslow JG, Nakhla T, Milcarek B, Hart J, LawryshPlunkett R, et al. Synchronized nasal intermittent positive pressure ventilation (SNIV) decreases work of breathing (WOB) in premature infants with respiratory distress syndrome (RDS) compared to nasal continuous positive airway pressure (NCPAP). Pediatr Pulmonol 2006;41(9):875-881.

15. Moretti C, Gizzi C, Papoff P, Lampariello S, Capoferri M, Calcagnini G, Bucci G. Comparing the effects of nasal synchronized intermittent positive pressure ventilation (nSIPPV) and nasal continuous positive airway pressure (nCPAP) after extubation in very low birth weight infants. Early Hum Dev 1999;56(2-3):167-177.

16. Lin CH, Wang ST, Lin YJ, Yeh TF. Efficacy of nasal intermittent positive pressure ventilation in treating apnea of prematurity. Pediatr Pulmonol 1998;26(5):349-353.

17. Ramos-Navarro C, Sanchez-Luna M, Sanz-López E, Maderuelo-Rodriguez E, Zamora-Flores E. Effectiveness of synchronized noninvasive ventilation to prevent intubation in preterm infants. AJP Rep 2016;6(3):e264-e271.

18. Chang HY, Claure N, D'ugard C, Torres J, Nwajei P, Bancalari E. Effects of synchronization during nasal ventilation in clinically stable preterm infants. Pediatr Res 2011;69(1):84-89.

19. Owen LS, Morley CJ, Davis PG. Effects of synchronisation during SiPAP-generated nasal intermittent positive pressure ventilation 


\section{EDITORIALS}

(NIPPV) in preterm infants. Arch Dis Child Fetal Neonatal Ed 2015; 100(1):F24-F30.

20. Itagaki T, Chenelle CT, Bennett DJ, Fisher DF, Kacmarek RM. Effects of leak compensation on patient-ventilator synchrony during premature/neonatal invasive and noninvasive ventilation: a lung model study. Respir Care 2017;62(1):22-33.

21. Greenough A, Rossor TE, Sundaresan A, Murthy V, Milner AD. Synchronized mechanical ventilation for respiratory support in newborn infants. Cochrane Database Syst Rev 2016;9:CD000456.

22. Cummings JJ, Polin RA; AAP the Committee on Fetus and Newborn. Noninvasive respiratory support. Pediatrics 2016;137(1): e20153758 [ePub ahead of print].

23. Beck J, Campoccia F, Allo JC, Brander L, Brunet F, Slutsky AS, Sinderby C. Improved synchrony and respiratory unloading by neurally adjusted ventilatory assist (NAVA) in lung-injured rabbits. Pediatr Res 2007;61(3):289-294.

24. Beck J, Reilly M, Grasselli G, Mirabella L, Slutsky AS, Dunn MS, Sinderby C. Patient-ventilator interaction during neurally adjusted ventilatory assist in low birth weight infants. Pediatr Res 2009;65(6): 663-668.

25. Colaizy TT, Kummet GJ, Kummet CM, Klein JM. Noninvasive neurally adjusted ventilatory assist in premature infants postextubation. Am J Perinatol 2017;34(6):593-598.

26. Gibu CK, Cheng PY, Ward RJ, Castro B, Heldt GP. Feasibility and physiological effects of noninvasive neurally adjusted ventilatory assist in preterm infants. Pediatr Res 2017;82(4):650-657.

27. Yonehara K, Ogawa R, Kamei Y, Oda A, Kokubo M, Hiroma T, Nakamura T. Non-invasive neurally adjusted ventilatory assist versus nasal intermittent positive-pressure ventilation in preterm infants born before 30 weeks' gestation. Pediatr Int 2018;60(10):957-961.

28. Jones M, Bai S, Thurman T, Holt S, Heulitt M, Courtney S. Comparison of work of breathing between noninvasive ventilation and neurally-adjusted ventilatory assist in a healthy and lung-injured piglet model. Respir Care 2018;63(12):1478-1484

29. Nilsestuen JO, Hargett KD. Using ventilator graphics to identify patient-ventilator asynchrony. Respir Care 2005;50(2):202-234; discussion 232-234.

30. Bordessoule A, Piquilloud L, Lyazidi A, Moreira A, Rimensberger PC. Imposed work of breathing during high-frequency oscillatory ventilation in spontaneously breathing neonatal and pediatric models. Respir Care 2018;63(9):1085-1093.

31. Smallwood CD, DiBlasi RM. Imposed work of breathing during high-frequency oscillation: I don't mean to impose. Respir Care 2018;63(9):1191-1193.

32. Ruiz Ferrón F, Serrano Simón JM. Conventional monitoring is not sufficient to assess respiratory effort during assisted ventilation. Med Intensiva 2018. doi: 10.1016/j.medin.2018.02.015. [Epub ahead of print]

33. Su PL, Kao PS, Lin WC, Su PF, Chen CW. Limited predictability of maximal muscular pressure using the difference between peak air- way pressure and positive end-expiratory pressure during proportional assist ventilation (PAV). Crit Care 2016;20(1):382.

34. Subirà C, de Haro C, Magrans R, Fernández R, Blanch L. Minimizing asynchronies in mechanical ventilation: current and future trends. Respir Care 2018;63(4):464-478.

35. Welty SE, Rusin CG, Stanberry LI, Mandy GT, Gest AL, Ford JM, et al. Short term evaluation of respiratory effort by premature infants supported with bubble nasal continuous airway pressure using Seattle-PAP and a standard bubble device. PLoS One 2018;13(3): e0193807.

36. Diblasi RM, Zignego JC, Tang DM, Hildebrandt J, Smith CV, Hansen TN, Richardson CP. Noninvasive respiratory support of juvenile rabbits by high-amplitude bubble continuous positive airway pressure. Pediatr Res 2010;67(6):624-629.

37. Weiler T, Kamerkar A, Hotz J, Ross PA, Newth CJL, Khemani RG. The relationship between high flow nasal cannula flow rate and effort of breathing in children. J Pediatr 2017;189:66-71.e3.

38. Shetty S, Hickey A, Rafferty GF, Peacock JL, Greenough A. Work of breathing during CPAP and heated humidified high-flow nasal cannula. Arch Dis Child Fetal Neonatal Ed 2016;101(5):F404-F407.

39. DiBlasi RM, Crotwell DN, Poli J, Hotz J, Cogen JD, Carter E. A pilot study to assess short-term physiologic outcomes of transitioning infants with severe bronchopulmonary dysplasia from ICU to two subacute ventilators. Can J Respir Ther 2018 Spring;54(1):1-6.

40. de Waal CG, van Leuteren RW, de Jongh FH, van Kaam AH, Hutten GJ. Patient-ventilator asynchrony in preterm infants on nasal intermittent positive pressure ventilation. Arch Dis Child Fetal Neonatal Ed 2018. doi: 10.1136/archdischild-2018-315102. [Epub ahead of print]

41. Owen LS, Manley BJ. Nasal intermittent positive pressure ventilation in preterm infants: Equipment, evidence, and synchronization. Semin Fetal Neonatal Med 2016;21(3):146-153.

42. Owen LS, Morley CJ, Dawson JA, Davis PG. Effects of non-synchronised nasal intermittent positive pressure ventilation on spontaneous breathing in preterm infants. Arch Dis Child Fetal Neonatal Ed 2011;96(6):F422-F428

43. Jasani B, Nanavati R, Kabra N, Rajdeo S, Bhandari V. Comparison of non-synchronized nasal intermittent positive pressure ventilation versus nasal continuous positive airway pressure as post-extubation respiratory support in preterm infants with respiratory distress syndrome: a randomized controlled trial. J Matern Fetal Neonatal Med 2016;29(10):1546-1551

44. Kahramaner Z, Erdemir A, Turkoglu E, Cosar H, Sutcuoglu S, Ozer EA. Unsynchronized nasal intermittent positive pressure versus nasal continuous positive airway pressure in preterm infants after extubation. J Matern Fetal Neonatal Med 2014;27(9):926-929.

45. Dumpa V, Katz K, Northrup V, Bhandari V. SNIPPV vs NIPPV: does synchronization matter? J Perinatol 2012;32(6):438-442. 